\title{
Role of portal color Doppler ultrasonography as noninvasive predictive tool for esophageal varices in cirrhotic patients
}

\author{
Mohamed Alaa ELdin Nouh ${ }^{1}$, Mohamed Kamel Abd-Elmageed ${ }^{2^{*}}\left(\mathbb{D}\right.$, Amany Abas Mohamed Amer ${ }^{1}$ and \\ Moamena Said ELhamouly ${ }^{1}$
}

\begin{abstract}
Background: Esophageal varices (EV) is the most common apprehensive complication of portal hypertension in patients with cirrhotic liver. Guidelines recommend Upper gastro-intestinal endoscopic screening for EV in patients with newly diagnosed chronic cirrhosis (Imperiale et al. in Hepatology 45(4):870-878, 2007). Yet, it is invasive, time consuming and costly. To avoid unnecessary endoscopy, some studies have suggested Doppler ultrasound examination as simple, and noninvasive tool in prediction and assessment of severity of EV (Agha et al. in Dig Dis Sci 54(3):654-660, 2009). Our study was to assess the role of different Doppler indices of portal vein, hepatic and splenic arteries as a noninvasive tool for prediction of esophageal varices in cirrhotic patients.

Results: This prospective case control study was conducted on 100 cirrhotic liver patients and 100 of healthy volunteers as control group. Patients were subjected to clinical examination, upper gastrointestinal tract endoscopy, abdominal ultrasonography with duplex Doppler evaluation of different portal Doppler hemodynamic indices were done for each patient. The results revealed that portal vein diameter, hepatic artery pulsatility index, portal hypertensive index, portal vein flow velocity, portal congestion index have high sensitivity for prediction of EV. However, Splenic artery resistance index, hepatic artery resistance index HARI, liver vascular index and platelet count/spleen diameter have less sensitivity for prediction of EV.
\end{abstract}

Conclusion: Measuring the portal hemodynamic indices can help physicians as noninvasive predictors of EV in cirrhotic patients to restrict the need for unnecessary endoscopic screening especially when endoscopic facilities are limited.

Keywords: Oesophageal varices, Portal hypertension, Doppler ultrasound

\section{Background}

Portal hypertension is defined as hepatic venous pressure gradient (HVPG) greater than $5 \mathrm{mmHg}$. HVPG is a surrogate for the portosystemic pressure gradient. Clinically significant portal hypertension is defined as a gradient greater than $10 \mathrm{mmHg}$ and variceal bleeding may occur at a gradient greater than $12 \mathrm{mmHg}$ [1].

\footnotetext{
*Correspondence: drmkamel01@gmail.com

${ }^{2}$ Department of Radiodiagnosis and Interventional Radiology, Menoufia

University Faculty of Medicine, Shebeen El-Kom, Egypt

Full list of author information is available at the end of the article
}

Esophageal varices is the most common clinical manifestation of portal hypertention. Bleeding varices is the most apprehensive complication contributing to high morbidity and mortality [2].The mortality associated with each episode of variceal bleeding ranges from 17 to $57 \%$ [3].

Because of the impact of upper gastrointestinal bleeding caused by rupture of EV in the prognosis of cirrhotic patients; the Baveno IV 2005 Consensus Workshop [1, 4] have determined that every patient diagnosed with cirrhosis should be investigated for EV, regardless of Child class and the cause of liver cirrhosis [5]. 
Franchis, et al. concluded that, endoscopic screening of all patients with liver cirrhosis would result in a large number of unnecessary endoscopies, additional burden to endoscopic units, high cost and the patient compliance with the screening program may be reduced. For these reasons, several studies have examined how to identify patients with varices using noninvasive or minimally invasive methods to avoid endoscopy in patients with a low risk of varices [6].

Various studies have suggested using ultrasonographic examination as simple, inexpensive, accurate and noninvasive technique. Moreover, various Doppler ultrasonographic indices have been shown to be of value in assessment of the severity of EV or risks of variceal bleeding in patients with cirrhosis.

\section{Methods}

\section{Study population}

This prospective case control study was conducted on 100 cirrhotic patients and 100 healthy volunteers as a control group. Cirrhotic patients were selected from 670 patients attending the outpatient and $/$ or inpatient department of Tropical Medicine and radiology department, in the period between October 2017 and August 2019. 570 patients were excluded due to presence of exclusion criteria.

Patients with liver cirrhosis, regardless the etiology of cirrhosis, were included in this study. While with of patients with hepatocellular carcinoma, active GIT bleeding, portal vein thrombosis, splenectomy or with other severe medical condition; end stage renal disease congestive heart failure or severe respiratory syndrome, were excluded.

\section{Patients were classified into two groups}

Cirrhotic group (Group 1) were 100 patients; 57(57\%) males and $43(43 \%)$ females. Their ages ranged from 36 to 78 years $(50.49 \pm 14.35)$. They were further classified into two subgroups after upper GI endoscopy; Group1-A: 67 Cirrhotic patients with esophageal varice and Group1-B: 33 Cirrhotic patients without esophageal varices.

Control group (Group 2) were 100 of healthy volunteers; $69(69 \%)$ males and $31(31 \%)$ females. Their ages ranged from 39 to 54 years $(39.21 \pm 13.98)$.

The study was approved by the local Research Ethics Committee of our institute; the reference number of approval: 10/2017-TROP-9. All patients and controls included in this research gave written informed consent to participate in this research.

\section{Examination protocol}

All patients were subjected to the following

- Full clinical assessment it was done by tropical medicine specialist whose experience more than 5 years in the clinical field. It includes:

- History taking With stress on history of haematemesis and melena, abdominal swelling, hepatic encephalopathy, fever, edema of lower limbs and jaundice.

- Complete General and Local examinations With stress on signs of liver cell failure.

- Laboratory investigations including Complete blood count. Liver function tests, Viral markers and Renal function tests.

- Child-Pugh classification was calculated for all studied patients to assess the severity of liver disease, depending on patients' clinical and laboratory data (16).

- Ultrasound examination (including grey scale and Doppler) was done to all patients and control groups by the same consultant radiologist blinded to study design with experience in Doppler ultrasound more than 12 years.

- The procedures was done by the equipment Toshiba Nemio XG apparatus (Toshiba, Japan) by with B-mode and color Duplex Doppler ultrasound at ultrasound unit of radiology department.

- All patients were kept in a fasting state $6 \mathrm{~h}$ before they were examined in the supine, right and left lateral positions during quiet respiration using a 2-5 MHz convex probe in transverse and longitudinal scans.

- B-mode Pelvi-abdominal ultrasound includes evaluation of:

- Liver as regarding its size, echopattern, cirrhosis, and focal lesions.

- Portal vein diameter (PVD; mm): It is measured at the hepatic hilum while the patient was in the supine position or in the left lateral decubitus position.

- Portal vein cross sectional area was measured.

- Spleen as regarding its size, echopattern and focal lesions. 
- Ascites as regarding amount (minimal, moderate or marked) and evidence of echoes, adhesions or loculations.

- Duplex Doppler ultrasound for assessment of:

- Portal venous system hemodynamics; includes assessment of:

- Portal vein patency and blood flow velocity (PVFV) $(\mathrm{cm} / \mathrm{s})$ :

- PVFV was measured in its mid-portion and was automatically calculated on samples of the Doppler signal lasting more than $4 \mathrm{~s}$. Three measurements were obtained and the average was used. Normal PVFV was $(15-20 \mathrm{~cm} / \mathrm{s})$ [7].

- Portal congestion index (PCI) was calculated using the following equation [8]:

- $\mathrm{PCI}=\frac{\text { Cross - sectional area of the portal vein }(\mathrm{cm} 2)}{\text { Mean portal vein velocity }(\text { Vmean })(\mathrm{cm} / \mathrm{s})}$

- Hepatic and splenic arterial hemodynamics includes assessment of:

- Hepatic artery resistance index (HARI) was calculated automatically using the following equation [9]:

- $\quad$ HARI $=\frac{\text { peak systolic velocity }(V \max )-\text { end diastolic velocity }(V \min )}{\text { peak systolic velocity(V } \max )}$

- Hepatic artery pulsatility index (HAPI) was calculated automatically using the following equation [10]:

- $\mathrm{HAPI}=\frac{\text { peak systolic velocity }(\mathrm{Vmax})-\text { end diastolic velocity }(\mathrm{Vmin})}{\text { mean velocity(Vmean) }}$

- Splenic artery resistance index (SARI) was measured automatically using the following equation [11]:

- $\mathrm{SARI}=\frac{\text { peak systolic velocity }(\mathrm{V} \max )-\text { end diastolic velocity }(\mathrm{V} \min )}{\text { peak systolic velocity }(\mathrm{V} \max )}$

- Liver vascular index (LVI) was calculated using this equation [10]:

- $\quad$ LVI $=\frac{\text { Portal venous flow velocity(PVFV) }}{\text { Hepatic arterial pulsatility index (HAPI) }}$

- Portal hypertensive index (PHI) was calculated using this equation [11]

- $\quad \mathrm{PHI}=\frac{\left(\mathrm{HARI}^{*} 0.69\right) \times\left(\mathrm{SARI}^{*} 0.87\right)}{\text { Portal vein mean velocity }(\text { Vmean })}$

- Calculation of platelet count/spleen diameter (PC/ $S D$ ) ratio by dividing number of platelets $/ \mathrm{ml}$ by the maximum bipolar diameter of spleen in millimeters estimated with pelvi abdominal ultrasound [12].

- Upper GIT endoscopy was done by to patients group by the same tropical medicine consultant blinded to study design with experience in GIT endoscopy more than 15 years.

- All patients with positive data after duplex Doppler ultrasound underwent upper gastrointestinal endoscopy that was performed using a videoscope (CLV-240; Olympus Ltd, Tokyo Japan) after fasting $6 \mathrm{~h}$ prior to endoscopy, positioned in left lateral position and given suitable sedation.

- Possible complications of procedures were explained to the patients and their relatives and written informed consents were obtained before the endoscope.

- Esophageal varices were graded by Paquet [13] grading system according to their size and depending on the degree of protrusion of varices into esophageal lumen when the esophagus was maximally relaxed.

- Grade 0 Absence of esophageal varices.

- Grade I Microcapillaries on esophagogastric transition or distal esophagus.

- Grade II 1 or 2 small varices located on distal esophagus.

- Grade III Medium sized varices.

- Grade IV Large varices in any part of the esophagus.

\section{Statistical analysis}

- Data were collected, tabulated, statistically analyzed using an IBM personal computer with Statistical Package of Social Science (SPSS) version 22 (SPSS, Inc, Chicago, Illinois, USA). Quantitative data were presented in the form of mean $(\bar{X})$, standard deviation (SD), range, and qualitative data were presented in the form of numbers and percentages. The significance were assessed using the chi-square $\left(\chi^{2}\right)$ and $Z$ test $(z)$ to study association between two qualitative variables, Student $t$-test for comparison between two groups having quantitative variables, Mann-Whitney and Kruskal-Wallis tests for comparison between two or more groups not normally distributed having quantitative variables. Logistic regression model as a predictive analysis test used to describe data and to explain the relationship between one dependent binary variable and one or more nominal, ordinal, interval or ratio-level independent variables. The receiver operating characteristic (ROC) curve was performed to determine. The cutoff value with the highest accuracy was selected as the diagnostic cutoff points. Sensitivity, specificity, positive predictive value (PPV), and negative predictive value (NPV) were determined. $p$ value was considered significant if less than 0.05 and highly significant if less than 0.001 (Figs. 1, 2, 3). 

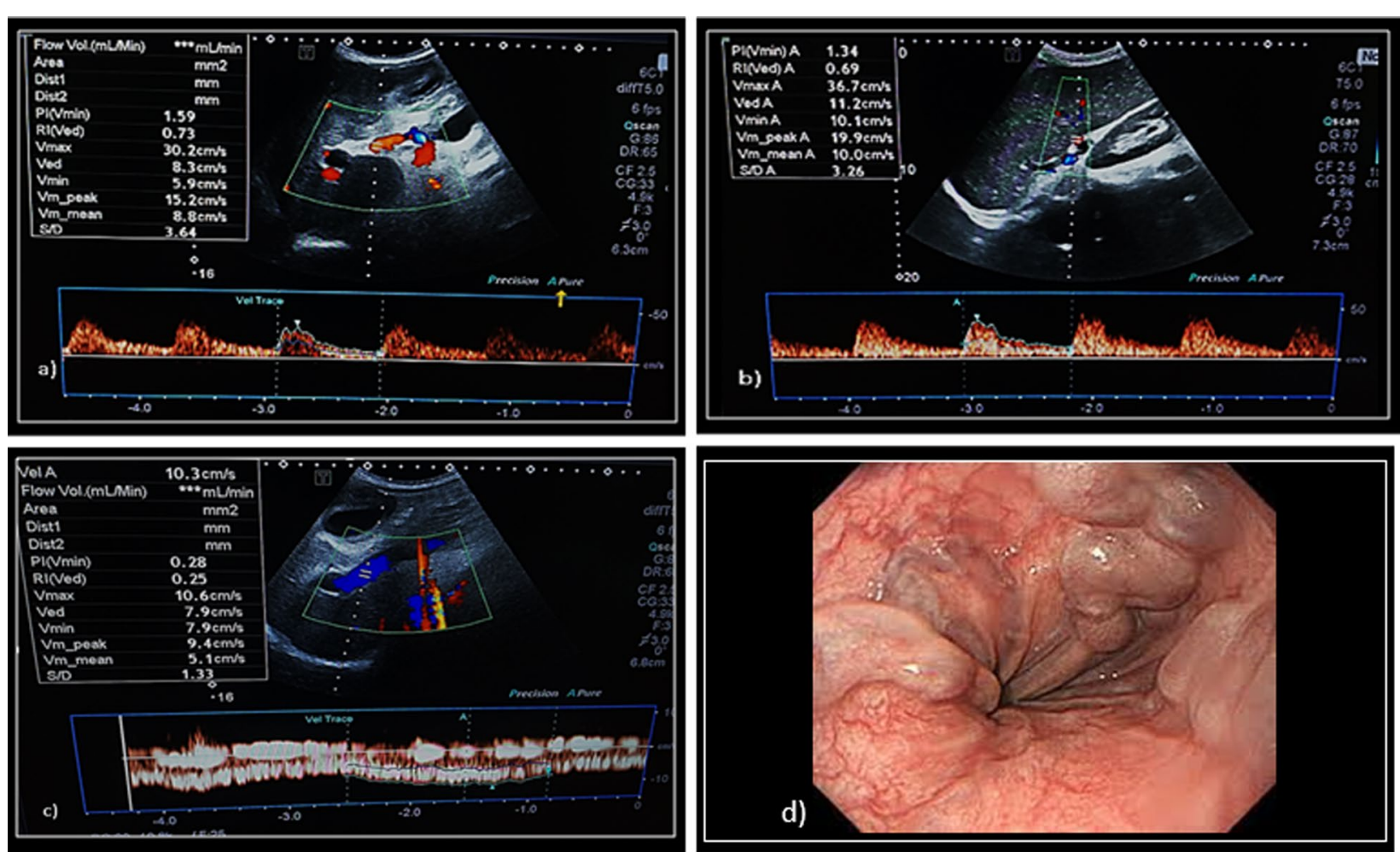

Fig. 167 Y male patient with chronic liver disease, a presents Doppler U/S of hepatic artery with HAPI: 2.60 and HARI: 0.84. b Presents Doppler U/S of splenic artery with SARI: 0.82 , the splenic bipolar diameter is $15.3 \mathrm{~cm}$. c PResents Doppler U/S of PV with MVPV: $9.4 \mathrm{~cm} / \mathrm{s}$. PV diameter is $15.0 \mathrm{~mm}$. d UGIE revealed grade IV oesophageal varices.

\section{Results}

As regards the demographic data of the studied cirrhotic groups, there was no statistical significant difference between the studied groups as regarding age and sex $(p$ value $>0.05$ ), Table 1 .

As regards the child classification, There was high statistical significant difference between group $1 \mathrm{~A}$ and group 1B ( $p$ value $<0.001)$, Table 2 .

There was statistical significant difference between group 1A and group 1B as regarding, liver echogenicity, spleen size, splenic collaterals and ascites ( $p$ value $<$ $0.05)$ but, there was no statistical significant difference between group 1A and group $1 \mathrm{~B}$ as regarding liver size $(p$ value $>0.05$ ), Table 3 .

There was high statistical significant difference between cirrhotic group and control group as regarding PVFV, PCI, HARI, HAPI, SARI and PHI ( $p$ value $<0.001)$ but, there was no statistical significant difference as regarding PVD and LVI ( $p$ value $>0.05$ ), Table 4 .

there was high statistical significant difference between group $1 \mathrm{~A}$ and group $1 \mathrm{~B}$ as regarding $\mathrm{PC} / \mathrm{SD}$ ratio and all measured portal hemodynamic indices $(p$ value $<0.001)$, Table 5 .
There was no statistical significant difference between the measured portal hemodynamic indices and the grade of EV ( $p$ value $>0.05)$ except PC/SD ratio and PVD ( $p$ value $<0.001)$, Table 6 .

A logistic regression model showed that Portal hypertensive index and Portal vein diameter are good predictors of the presence of esophageal varices more than Liver vascular index Table 7.

The accuracy of PC/SD ratio and portal hemodynamic indices in prediction of esophageal varices are shown in Table 8.

\section{Discussion}

Variceal bleeding occurs in $20-40 \%$ of cirrhotic patients with esophageal varices and is associated with a high morbidity and mortality [2]. The Baveno IV 2005 Consensus Workshop [1, 4] have determined that every patient diagnosed with cirrhosis should be investigated for EV, regardless of Child class and the cause of liver cirrhosis [5].

Several studies have examined how to identify patients with varices using noninvasive methods to avoid large number of unnecessary screening endoscopy in patients with a low risk of varices [6]. Various portal 

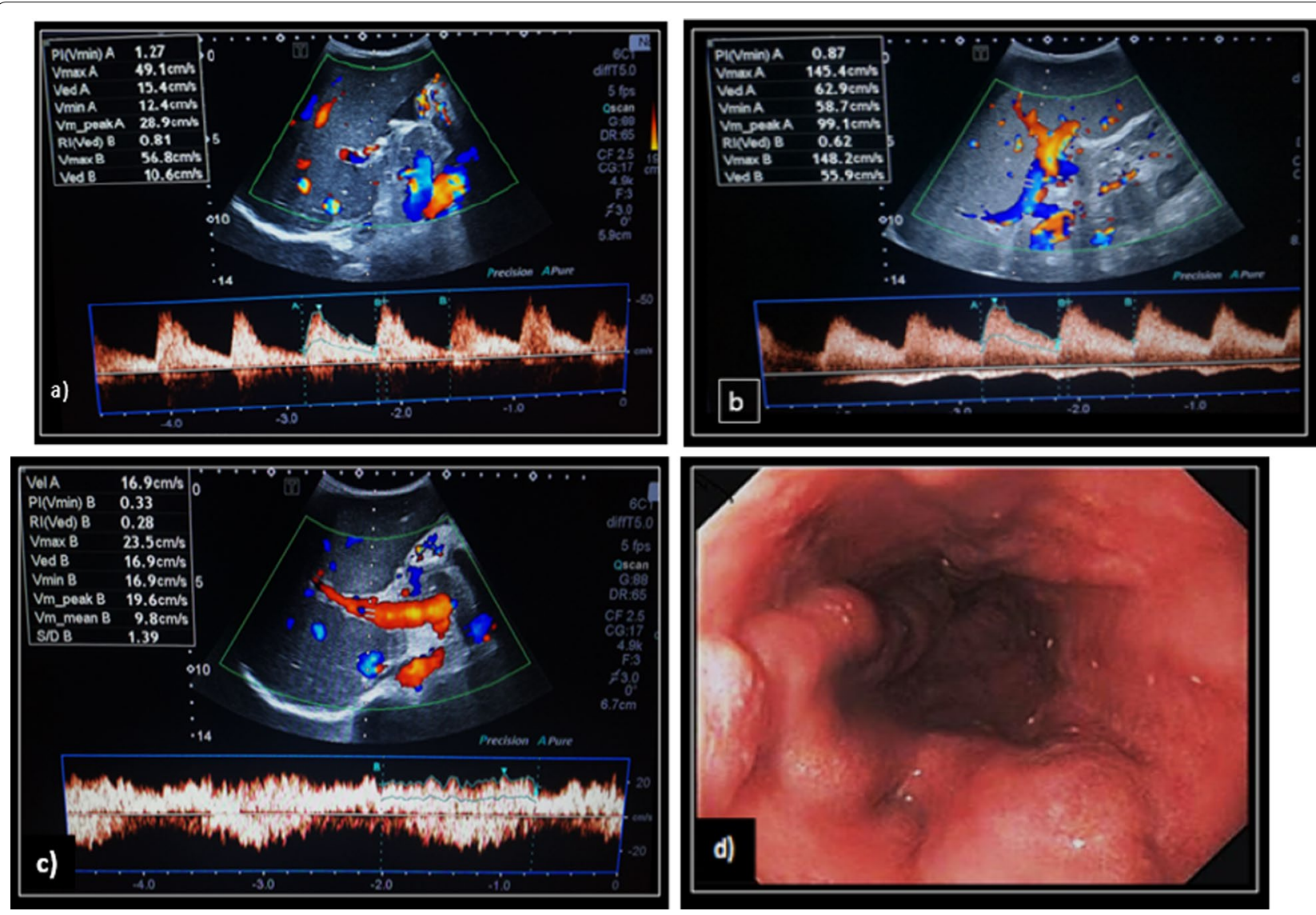

Fig. 252 y male patient with chronic liver disease, a presents Doppler U/S of hepatic artery with HAPI: 1.27 and HARI: 0.81. b Presents Doppler U/S of splenic artery with SARI: 0.62 , the splenic bipolar diameter is $18 \mathrm{~cm}$. c Presents Doppler U/S of PV with MVPV: $19.6 \mathrm{~cm} / \mathrm{s}$. PV diameter is $14 \mathrm{~mm}$. ascites was also noticed. $\mathbf{d}$ UGIE revealed grade III oesophageal varices.

haemodynamic indices have been shown to be predictive of the severity of EV or risks of variceal bleeding in patients with cirrhosis [14].

This prospective case control study was conducted on 2 groups: group 1, 100 cirrhotic patients which was classified into two subgroups after upper GI endoscopy; group1A, cirrhotic patients with esophageal varices and Group1B, cirrhotic patients without esophageal varices, and group 2, 100 of healthy volunteers as a control group.

As regards the demographic data of the studied cirrhotic groups, $57 \%$ of cirrhotic patients were males and $43 \%$ were females. Their ages ranged from 36 to 78 years $(49.31 \pm 14.27)$ in group $1 \mathrm{~A}$ and $(52.88 \pm 14.45)$ in group 1B. these observations go in agreement with with Tharwa et al. [15], where males were $59.4 \%$ and Hekmatnia et al. [16], who found that, the mean age was 52.1 years (range: 28-83 years).

In our study, there was high statistical significant difference between group $1 \mathrm{~A}$ and group $1 \mathrm{~B}$ as regarding child classification $(p$ value $<0.001)$. This was proven by [17], Nashaat et al. [18], and Zaman et al. [19], who reported that, patients in Child B or C are nearly 3 times more likely to have varices than those in Child A.

Concerning pelvi-abdominal ultrasound findings, there was high statistical significant difference between group1A and group1B regarding portal vein diameter (PVD), liver echogenecity, spleen size, and splenic collaterals $(p$ value $<0.001)$. These results were in agreement with Faisal et al. [20], and Khalil et al. [21], who concluded that, increased PVD, splenomegaly and presence of splenic collaterals by ultrasound can predict EV specially the large varices. However, This result was in controversy with Berzigotti et al. [22], who found that, there was no significant change in liver echogenicity in cirrhotic patients with varices than patients without varices.

In our study, there was no significant difference in PVD $(\mathrm{mm})$ in cirrhotic patients $(12.4 \pm 3.2)$ compared with the controls $(12.1 \pm 1.2)$ with ( $p$ value $>0.05)$. However, There was high significant increase in PVD in group 1A $(13.9 \pm 2.2)$ than group $1 \mathrm{~B}(9.4 \pm 2.8)$ with $(p$ value < $0.001)$ with high statistical significant increase with the grades of EV with $(p$ value $<0.001)$. These results were 

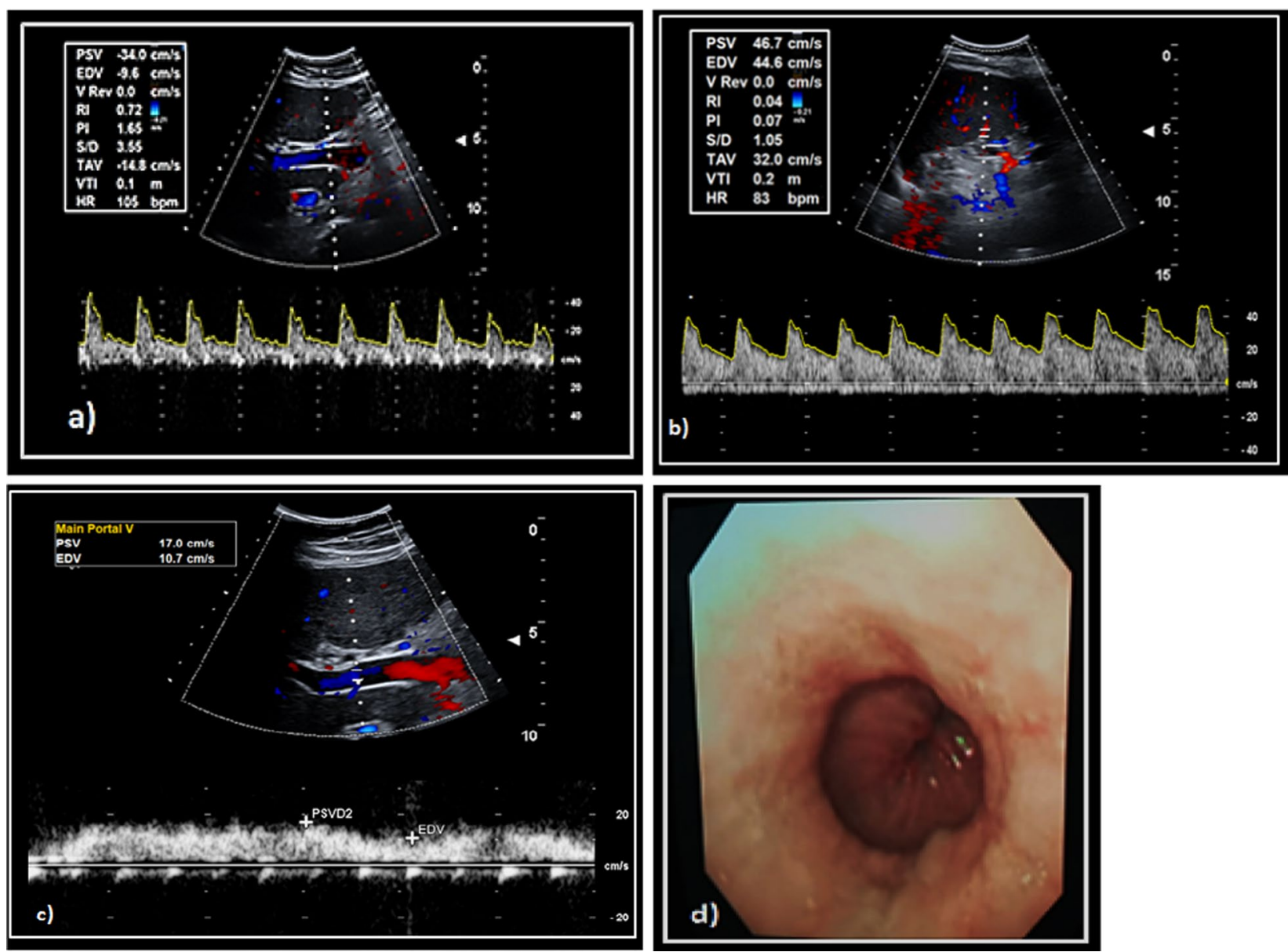

Fig. $351 \mathrm{y}$ female patient with chronic liver disease, a presents Doppler U/S of hepatic artery with HAPI: 1.6 and HARI: 0.72 . b presents Doppler U/S of splenic artery with SARI: 0.45 , the splenic bipolar diameter is $14.5 \mathrm{~cm}$. c presents Doppler U/S of PV with MVPV: $13.6 \mathrm{~cm} / \mathrm{s}$. PV diameter is $11.5 \mathrm{~mm}$. d UGIE revealed grade I oesophageal varices.

Table 1 Demographic data of the studied groups

\begin{tabular}{lllll}
\hline Variable & $\begin{array}{l}\text { Group1A } \\
\text { Cirrhotic Pt. with EV } \\
(\boldsymbol{n}=\mathbf{6 7 )} \\
\boldsymbol{M} \pm \text { SD }\end{array}$ & $\begin{array}{l}\text { Group1B } \\
\text { Cirrhotic Pt. without EV } \\
(\mathbf{n}=\mathbf{3 3}) \\
\mathbf{M} \pm \mathbf{S D}\end{array}$ & $\begin{array}{l}\text { Control group } \\
(\boldsymbol{n}=\mathbf{1 0 0}) \\
\boldsymbol{M} \pm \text { SD }\end{array}$ & Test of significance \\
\hline Age & $49.31 \pm 14.27$ & $52.88 \pm 14.45$ & $50.33 \pm 13.3$ & $\begin{array}{l}\text { (Kruskal-Wallis test) } \\
<0.48^{\mathrm{NS}}\end{array}$ \\
Sex & $N(\%)$ & $N(\%)$ & $N(\%)$ & $X^{2}$ test $=3.72$ \\
Male & $40(59.7 \%)$ & $17(51.5 \%)$ & $69(69 \%)$ & $0.16^{\mathrm{NS}}$ \\
\hline Female & $27(40.3 \%)$ & $16(48.5 \%)$ & $31(31 \%)$ & \\
\hline
\end{tabular}

NS no significant difference

in agreement with Anda et al. [23], Sarwar et al. [24] and Kayacetin et al. [25] who found an association between an increase in PVD with liver cirrhosis, presence and grading of EV as well. But these results were in disagreement with Jaheen et al. [26], who concluded that, PVD is not sensitive to presence of cirrhosis or in differentiation between the grades of EV presence.

In our study, at a cutoff point (10.4), the sensitivity of PVD that can predict EV was $94.03 \%$, the specificity was $75.76 \%$, PPV was $88.73 \%$, NPV was $86.21 \%$, 
Table 2 Child classification of the studied groups

\begin{tabular}{lllll}
\hline $\begin{array}{l}\text { Child } \\
\text { classification }\end{array}$ & $\begin{array}{l}\text { Group 1A } \\
(\boldsymbol{n}=\mathbf{6 7 )}\end{array}$ & $\begin{array}{l}\text { Group 1B } \\
(\boldsymbol{n}=\mathbf{3 3})\end{array}$ & $\begin{array}{l}\text { Test of } \\
\text { significance }\end{array}$ & $\boldsymbol{p}$ Value \\
\hline A:31 & $13(19.4 \%)$ & $18(54.5 \%)$ & $x^{2}$ test & $0.001^{*}$ \\
B:33 & $23(34.3 \%)$ & $10(30.3 \%)$ & 14.86 & \\
C:36 & $31(46.3 \%)$ & $5(15.2 \%)$ & & \\
\hline
\end{tabular}

*High significant difference, $\mathrm{P}<0.001$

Table 3 Pelvi abdominal ultrasound findings of the studied groups

\begin{tabular}{|c|c|c|c|c|}
\hline & $\begin{array}{l}\text { Group 1A } \\
(n=67) \\
N(\%)\end{array}$ & $\begin{array}{l}\text { Group 1B } \\
(n=33) \\
N(\%)\end{array}$ & $\begin{array}{l}\text { Test of } \\
\text { significance }\end{array}$ & $p$ Value \\
\hline Liver size & & & Fisher exact & $0.22^{\mathrm{NS}}$ \\
\hline $\begin{array}{l}\text { Shrunken } \\
(<12 \mathrm{~cm})\end{array}$ & $22(32.8 \%)$ & $6(18.2 \%)$ & & \\
\hline $\begin{array}{l}\text { Normal } \\
(12-16 \mathrm{~cm})\end{array}$ & $44(65.7 \%)$ & $27(81.8 \%)$ & & \\
\hline $\begin{array}{l}\text { Enlarged } \\
(>16 \mathrm{~cm})\end{array}$ & $1(1.5 \%)$ & $0(0 \%)$ & & \\
\hline Splenic size & & & $x^{2}$ test 63.4 & $<0.001^{*}$ \\
\hline $\begin{array}{l}\text { Normal } \\
(7-11 \mathrm{~cm})\end{array}$ & $1(1.5 \%)$ & $25(75.8 \%)$ & & \\
\hline $\begin{array}{l}\text { Enlarged } \\
(>11 \mathrm{~cm})\end{array}$ & $66(98.5 \%$ & $8(24.2 \%)$ & & \\
\hline Liver echogenecity & & & $x^{2}$ test 15.97 & $<0.001^{*}$ \\
\hline Coarse & $60(89.6 \%)$ & $18(54.5 \%)$ & & \\
\hline Homogeneous & $7(10.4 \%)$ & $15(45.5 \%)$ & & \\
\hline Splenic collaterals & & & $x^{2}$ test 22.46 & $<0.001^{*}$ \\
\hline Yes & $37(55.2 \%)$ & $2(6.1 \%)$ & & \\
\hline No & $30(44.8 \%)$ & $31(93.9 \%)$ & & \\
\hline Ascites & & & $x^{2}$ test 11.86 & $0.008^{*}$ \\
\hline No & 23(34.3\%) & 23(69.7\%) & & \\
\hline Mild & $11(16.4 \%)$ & $4(12.1 \%)$ & & \\
\hline Moderate & 19(28.9\%) & $4(12.1 \%)$ & & \\
\hline Marked & $14(20.9 \%)$ & $2(6.1 \%)$ & & \\
\hline
\end{tabular}

*High significant difference, $\mathrm{P}<0.001$

accuracy was $88 \%$ and AUC $=0.877$. These results were in agreement with Berzigotti et al. [22] and Nouh et al. [27] who found the best cut-off value of PVD for EV prediction was (10.7) and (11.5) respectively.

Regarding platelet count/spleen diameter ratio (PC/ $\mathrm{SD})$, there was high statistical significant difference in group 1A (546 \pm 290.9$)$ than group 1B $(1135 \pm 413.2)$ and the grades of EV $(725.6 \pm 273.5)(567.9 \pm 280.2)$ $(347.8 \pm 162.6)(293.8 \pm 91.8)$ in grades I, II, III and IV respectively as well ( $p$ value $<0.001$ ). This result was in agreement with Shekar et al. [12], Agha et al. [28], and Elhady et al. [29], who who explained the decrease in $\mathrm{PC} / \mathrm{SD}$ ratio by increase in spleen size and thrombocytopenia which usually occur with increase of portal pressure and with development of varices especially with larger risky varices.

Our study showed that, at cutoff point (604), the sensitivity of $\mathrm{PC} / \mathrm{SD}$ ratio that can predict the presence of EV was $61.19 \%$, the specificity was $90.91 \%$, PPV was $93.18 \%$, NPV was $53.57 \%$, accuracy was $71.00 \%$ and $\mathrm{AUC}=0.883$. These results were in agreement with studies of Shekar et al. [12], Sheta et al. [30] and Nouh et al. [27], who reported that, at cut-off values around (600), PC/SD ratio that can predict EV with similar sensitivity, specificity, PPV \& NPV.

Regarding the measured portal hemodynamic indices by Duplex Doppler ultrasound, there was high significant decrease of portal vein flow velocity (PVFV) $(\mathrm{cm} / \mathrm{s})$, in cirrhotic patients $(15.3 \pm 5.1)$ compared with controls $(18.2 \pm 2.9)$ with $(p<0.001)$ with high significant decrease in in group $1 \mathrm{~A}(12.2 \pm 2.3)$ than group $1 \mathrm{~B}$ $(21.4 \pm 3.2)$ with $(p$ value $<0.001)$. Studies were done by Elhady et al. [29], Mahmoud et al. [31] and Liu et al., [32] reported that (PVFV) was significantly lower in cirrhotic patients than controls. Anda et al. [23] and Elbarbary et al. [33] Also, found that, PVFV was lower in patients with EV. In contrast, Schneider et al. [34] and Piscaglia et al. [35] reported that, no change in PVFV between patients and controls. This may be due to intra- and inter observer variability or presence of collaterals which affect the velocity.

Our study showed that, at cutoff point (15.2), the sensitivity of PVFV that can predict EV was $89.55 \%$, the specificity was $93.94 \%$, PPV was $96.77 \%$, NPV was $81.58 \%$, accuracy was $91.00 \%$ and AUC $=0.953$. These results were in agreement with Minal et al. [36] who reported that, PVFV had a high sensitivity $84 \%$ for detecting the EV.

Regarding the portal congestion index (PCI) there was a significant increase in cirrhotic patients $(0.11 \pm$ $0.045)$ compared with the controls $(0.071 \pm 0.012)$ and increase in group $1 \mathrm{~A}(0.1 \pm 0.03)$ than group1B $(0.05$ $\pm 0.0 .1)$ with $(p$ value $<0.001)$. These results were in agreement with Kayacetin et al. [25] who found that, PCI was significantly increased in cirrhotic group and in presence of EV.

At cutoff point $(0.1)$, the sensitivity of $\mathrm{PCI}$ that can predict EV was $89.35 \%$, the specificity was $92.84 \%$, PPV was 95.66\%, NPV was $82.5 \%$, accuracy was $93 \%$ and AUC = 0.948. this was in agreement with Moriyasu et al. [8], who found that, cutoff point was (0.189) in patients with EV with sensitivity (84.65\%) and Lee et al. [37], who found that PCI cutoff point was (0.089).

Regarding arterial indices including HARI, HAPI and SARI, there was high significant increase in the in 
Table 4 Comparison of portal vein diameter and different hemodynamic indices by B-mode and color Doppler US between cirrhotic group and control group

\begin{tabular}{|c|c|c|c|}
\hline Normal values & $\begin{array}{l}\text { Cirrhotic group (G1) } \\
(n=100) \\
M \pm \text { SD }\end{array}$ & $\begin{array}{l}\text { Control group (G2) } \\
(n=100) \\
M \pm \text { SD }\end{array}$ & $\begin{array}{l}p \text { Value (Mann- } \\
\text { Whitney test) }\end{array}$ \\
\hline $\begin{array}{l}\text { Portal vein flow velocity (PVFV) } \\
(15-20 \mathrm{~cm} / \mathrm{s})\end{array}$ & $15.3 \pm 5.1$ & $18.2 \pm 2.9$ & $<0.001^{*}$ \\
\hline $\begin{array}{l}\text { Portal vein diameter (PVD) } \\
(10-13 \mathrm{~mm})\end{array}$ & $12.4 \pm 3.2$ & $12.1 \pm 1.2$ & $0.38^{\mathrm{NS}}$ \\
\hline $\begin{array}{l}\text { Portal congestion index }(\mathrm{PCl}) \\
(0.07-0.1)\end{array}$ & $0.11 \pm 0.045$ & $0.071 \pm 0.012$ & $<0.001^{*}$ \\
\hline $\begin{array}{l}\text { Hepatic artery resistive index (HARI) } \\
(0.5-0.7)\end{array}$ & $0.71 \pm 0.052$ & $0.51 \pm 0.03$ & $<0.001^{*}$ \\
\hline $\begin{array}{l}\text { Hepatic artery pulsatility index (HAPI) } \\
(0.9-1)\end{array}$ & $1.34 \pm 0.12$ & $1.01 \pm 0.04$ & $<0.001^{*}$ \\
\hline $\begin{array}{l}\text { Splenic artery resistive index (SARI) } \\
(0.5-0.7)\end{array}$ & $0.7 \pm 0.05$ & $0.5 \pm 0.06$ & $<0.001^{*}$ \\
\hline $\begin{array}{l}\text { Portal hypertensive index (PHI) } \\
(1.3-1.8)\end{array}$ & $2.23 \pm 0.85$ & $1.38 \pm 0.53$ & $<0.001^{*}$ \\
\hline $\begin{array}{l}\text { Liver vascular index (LVI) } \\
(10-15)\end{array}$ & $11.77 \pm 4.95$ & $11.61 \pm 3.2$ & $0.78^{\mathrm{NS}}$ \\
\hline
\end{tabular}

NS $=$ no significant difference, $\mathrm{P}>0.05$

*High significant difference, $\mathrm{P}<0.001$

Table 5 Comparison of different predictors in the studied groups in relation to presence of esophageal varices

\begin{tabular}{lccc}
\hline & $\begin{array}{l}\text { Group 1A } \\
(\boldsymbol{n}=\mathbf{6 7}) \\
\boldsymbol{M} \pm \text { SD }\end{array}$ & $\begin{array}{l}\text { Group 1B } \\
(\boldsymbol{n}=\mathbf{3 3}) \\
\boldsymbol{M} \pm \mathbf{S D}\end{array}$ & $\begin{array}{l}\boldsymbol{p} \text { value } \\
\text { (Mann- } \\
\text { Whitney } \\
\text { test) }\end{array}$ \\
\hline $\begin{array}{l}\text { Platelet count/spleen diam- } \\
\text { eter (PC/SD) ratio }\end{array}$ & $546 \pm 290.9$ & $1135 \pm 413.2$ & $<0.001^{*}$ \\
Portal vein flow velocity & $12.2 \pm 2.3$ & $21.4 \pm 3.2$ & $<0.001^{*}$ \\
Portal vein diameter & $13.9 \pm 2.2$ & $9.4 \pm 2.8$ & $<0.001^{*}$ \\
Portal congestion index & $0.1 \pm 0.03$ & $0.05 \pm 0.01$ & $<0.001^{*}$ \\
Hepatic artery resistive index & $0.7 \pm 0.03$ & $0.6 \pm 0.03$ & $<0.001^{*}$ \\
Hepatic artery pulsatility index & $1.4 \pm 0.09$ & $1.2 \pm 0.1$ & $<0.001^{*}$ \\
Splenic artery resistive index & $0.7 \pm 0.02$ & $0.64 \pm 0.02$ & $<0.001^{*}$ \\
Portal hypertensive index & $2.7 \pm 0.46$ & $1.2 \pm 0.3$ & $<0.001^{*}$ \\
Liver vascular index & $8.8 \pm 1.88$ & $17.8 \pm 3.57$ & $<0.001^{*}$ \\
\hline
\end{tabular}

*High significant difference, $\mathrm{P}<0.001$

cirrhotic patients than the controls $(p<0.001)$ with SARI showed high statistically significant difference between group 1A and group 1B ( $p$ value $<0.001)$, These results were in agreement with Park et al. [38], Zhang et al. [9], Piscaglia et al. [35] Dewidar et al. [39] and Nicolau et al. [40] who found increase in the arterial indices in cirrhotic patients than in controls and in pateints with varices than patients without.

This study showed that, at cutoff point (0.71), the sensitivity of HARI that can predict EV was $76.12 \%$, the specificity was $91.23 \%$, PPV was $92.11 \%$, NPV was $67.35 \%$, accuracy was $84.00 \%$ and AUC $=0.881$. Concerning SARI, at cutoff point $(0.72)$, the sensitivity of SARI that can predict EV was $77.61 \%$, the specificity was $92.56 \%$, PPV was $93.98 \%$, NPV was $68.75 \%$, accuracy was $85 \%$ and AUC $=0.888$. These results were in agreement with Child et al. [41] and Dib et al. [42]who found that, the presence of EV affect all measured hepatic and splenic arterial hemodynamic parameters with the best cut off point for SARI for prediction of EV was (0.76) with sensitivity of $85 \%$ and specificity of $77.5 \%$.

This study showed that, at cutoff point(1.3), the sensitivity of HAPI that can predict EV was $94.03 \%$, the specificity was $66.67 \%$, PPV was $85.14 \%$, NPV was $84.62 \%$, accuracy was $85.00 \%$ and AUC $=0.858$. These results were in agreement with a study of Haktanir et al. [43], who reported that, HAPI was significantly higher in EV with a cutoff point (1.28).

In this study there was no statistical significant difference between the measured portal hemodynamic indices and the grade of EV ( $p$ value $>0.05$ ) except $\mathrm{PC} / \mathrm{SD}$ ratio and PVD as fore-mentioned. These results were in agreement with a study done by Hekmatnia et al., who found that, there was no significant relationship between PCI, arterial resistance and pulsatility indices and the grades of EV [16].

In contrast, results published by Anda et al. [23], showed a significant increase in PCI, HARI and HAPI with higher grades of $\mathrm{EV}$, this could be attributed to the difference in the number of selected cirrhotic patients 
Table 6 Comparison of different predictors in the studied groups in relation to the grade of esophageal varices

\begin{tabular}{|c|c|c|c|c|c|}
\hline $\begin{array}{l}\text { Esophageal varices } \\
N=67\end{array}$ & $\begin{array}{l}\text { Grade } 1 \\
(n=26) \\
M \pm S D\end{array}$ & $\begin{array}{l}\text { Grade } 2 \\
(n=18) \\
M \pm S D\end{array}$ & $\begin{array}{l}\text { Grade } 3 \\
(n=14) \\
M \pm S D\end{array}$ & $\begin{array}{l}\text { Grade } 4 \\
(n=9) \\
M \pm S D\end{array}$ & $\begin{array}{l}p \text { value } \\
\text { (Kruskal Wallis test) }\end{array}$ \\
\hline $\mathrm{PC} / \mathrm{SD}$ ratio & $725.6 \pm 273.5$ & $567.9 \pm 280.2$ & $347.8 \pm 162.6$ & $293.8 \pm 91.8$ & $<0.001^{*}$ \\
\hline Portal vein flow velocity & $12.7 \pm 2.4$ & $12.2 \pm 1.2$ & $11.9 \pm 3.5$ & $11.7 \pm 1.3$ & $0.327^{\mathrm{NS}}$ \\
\hline Portal vein diameter & $12.67 \pm 2.24$ & $14.14 \pm 1.7$ & $14.74 \pm 1.79$ & $14.68 \pm 1.7$ & $0.001^{*}$ \\
\hline Portal congestion index & $0.13 \pm 0.03$ & $0.14 \pm 0.03$ & $0.14 \pm 0.03$ & $0.14 \pm 0.03$ & $0.551^{\mathrm{NS}}$ \\
\hline Hepatic artery resistive index & $0.7 \pm 0.03$ & $0.7 \pm 0.03$ & $0.7 \pm 0.03$ & $0.7 \pm 0.03$ & $0.962^{\mathrm{NS}}$ \\
\hline Hepatic artery pulsatility index & $1.4 \pm 0.08$ & $1.4 \pm 0.12$ & $1.4 \pm 0.07$ & $1.3 \pm 0.08$ & $0.303^{\mathrm{NS}}$ \\
\hline Splenic artery resistive index & $0.7 \pm 0.02$ & $0.7 \pm 0.02$ & $0.7 \pm 0.02$ & $0.7 \pm 0.01$ & $0.390^{\mathrm{NS}}$ \\
\hline Portal hypertensive index & $2.7 \pm 0.65$ & $2.7 \pm 0.31$ & $2.5 \pm 0.51$ & $2.8 \pm 0.27$ & $0.210^{\mathrm{NS}}$ \\
\hline Liver vascular index & $9.1 \pm 1.98$ & $8.6 \pm 1.11$ & $8.6 \pm 2.8$ & $8.7 \pm 1.25$ & $0.581^{\mathrm{NS}}$ \\
\hline
\end{tabular}

NS $=$ no significant difference, $P>0.05$

*High significant difference, $\mathrm{P}<0.001$

and different degree of decompensation between these studies [23].

Regarding portal hypertensive index (PHI) there was high statistical significant increase in PHI in cirrhotic group than control group with ( $p$ value $<0.001)$, with high statistical significant increase in PHI in group $1 \mathrm{~A}$ than group 1B with ( $p$ value $<0.001)$. this was in agreement with Iwao et al. [44] who found that, PHI had a

Table 7 Logestic regression model to predict the presence of esophageal varices in the studied groups

\begin{tabular}{lllr}
\hline & $\boldsymbol{p}$ Value & Odds ratio & \multicolumn{1}{c}{$\mathbf{9 5 \%} \mathbf{C l}$} \\
\hline Liver vascular index & 0.202 & 0.688 & $0.387-1.222$ \\
Portal hypertensive index & 0.021 & 0 & $0-0.231$ \\
Portal vein diameter & 0.029 & 0.520 & $0.289-0.935$ \\
\hline
\end{tabular}

specificity $>70 \%$ when comparing cirrhotic patients with controls and also in agreement with Faisal et al. [20] who found that, PHI showed statistically significantly higher values in patients with $\mathrm{EV}$ than those without $\mathrm{EV}$.

At cutoff point (1.48), the sensitivity of PHI that can predict EV was $92.43 \%$, the specificity was $93.94 \%$, PPV was $97.10 \%$, NPV was $96.45 \%$, accuracy was $95.00 \%$ and AUC $=0.992 . \%$. These results were in agreement with Abu El Makarem et al. [45] who found that, only PHI had an independent predictive value of EV and suggested the beginning of endoscopic screening in patients with compensated cirrhosis at a cutoff point of PHI $(>2.08)$.

As regards, the liver vascular index (LVI), there was no significant difference in cirrhotic patients compared with the controls ( $p$ value $>0.05$ ), this result was in controversy with Jaheen et al. [26], who found that, LVI was

Table 8 Accuracy of PC/SD ratio and portal hemodynamic indices in prediction of esophageal varices

\begin{tabular}{|c|c|c|c|c|c|c|c|}
\hline Index & Cutoff & Sensitivity (\%) & Specificity (\%) & PPV (\%) & NPV (\%) & Accuracy (\%) & AUC \\
\hline $\begin{array}{l}\mathrm{PC/SD} \text { ratio } \\
\text { Inversely proportional }\end{array}$ & 604 & 61.19 & 90.91 & 93.18 & 53.57 & 71.00 & 0.883 \\
\hline $\begin{array}{l}\text { Portal vein flow velocity }(\mathrm{cm} / \mathrm{s}) \\
\text { Inversely proportional }\end{array}$ & 15.2 & 89.55 & 93.94 & 96.77 & 81.58 & 91.00 & 0.953 \\
\hline $\begin{array}{l}\text { Portal vein diameter }(\mathrm{mm}) \\
\text { Directly proportional }\end{array}$ & 10.4 & 94.03 & 75.76 & 88.73 & 86.21 & 88 & 0.877 \\
\hline $\begin{array}{l}\text { Portal congestion index } \\
\text { Directly proportional }\end{array}$ & 0.1 & 89.35 & 92.84 & 95.66 & 82.5 & 93 & 0.948 \\
\hline $\begin{array}{l}\text { Hepatic artery resistive index } \\
\text { Directly proportional }\end{array}$ & 0.71 & 76.12 & 91.23 & 92.11 & 67.35 & 84.00 & 0.881 \\
\hline $\begin{array}{l}\text { Hepatic artery pulsatility index } \\
\text { Directly proportional }\end{array}$ & 1.3 & 94.01 & 66.67 & 85.14 & 84.62 & 85.00 & 0.858 \\
\hline $\begin{array}{l}\text { Splenic artery resistive index } \\
\text { Directly proportional }\end{array}$ & 0.72 & 77.61 & 92.56 & 93.98 & 68.75 & 85 & 0.888 \\
\hline $\begin{array}{l}\text { Portal hypertensive index } \\
\text { Directly proportional }\end{array}$ & 1.48 & 92.43 & 93.94 & 97.10 & 96.45 & 95.00 & 0.992 \\
\hline $\begin{array}{l}\text { Liver vascular index } \\
\text { Inversely proportional }\end{array}$ & 9.4 & 74.63 & 96.97 & 98.04 & 65.31 & 82.00 & 0.973 \\
\hline
\end{tabular}


significantly lower in cirrhotic patients than controls with ( $p$ value $=0.018)$.

There was high statistical significant decrease in LVI in group 1A than group 1B with ( $p$ value $<0.001)$, this result was in agreement with a study done by Faisal et al. [20], who found that, LVI was lower in patients with EV ( $p$ value $=0.001)$.

At cutoff point (9.4), the sensitivity of LVI that can predict EV was $74.63 \%$, the specificity was $96.97 \%$, PPV was 98.04\%, NPV was $65.31 \%$, accuracy was $82.00 \%$ and AUC $=0.973$. These results were in agreement with Haktanir et al. [43], who found that, the best cut off point for LVI for prediction of EV was (10.36) with sensitivity of $85 \%$ and specificity of $77 \%$ and concluded that, LVI was a high sensitive and specific parameter in the diagnosis and prediction of EV.

However, Piscaglia et al., and Jeon et al., have reported different findings in the measured portal hemodynamic indices compared with the present study results. They reported that, Doppler measurements were not useful in distinguishing patients with liver cirrhosis from healthy individuals. However, clinical tests including biochemistry and ultrasonography would be useful in selecting eligible patients for screening endoscopy $[46,47]$. This could be attributed to the difference in the number of patient and control groups, the difference in etiology of liver cirrhosis in western countries, and difference in the degree of hepatic decompensation.

Additional studies are required in a larger number of cirrhotic patients of different etiologies and different grades of Child classification for validation of portal hemodynamic indices and to determine universal best cut off values that can be safely recommended as noninvasive predictors of esophageal varices.

\section{Conclusion}

From this study, we concluded that Measuring the portal vein diameter and portal hemodynamic indices especially (HAPI, PHI, PVFV and PCI) can help physicians as noninvasive predictors of $\mathrm{EV}$ in cirrhotic patients to restrict the need for unnecessary endoscopic screening. This is especially useful in clinical settings where resources are limited and endoscopic facilities are not present in all areas. Platelet count/spleen diameter ratio and can help physicians to grade esophageal varices in cirrhotic patient.

\footnotetext{
Abbreviations

AUC: Area under curve; Cl: Confidence interval; Cm/S: Centimeter/second; EV: Esophageal varices; PV: Portal vein; P value: Probability value; HARI: Hepatic artery resistance index; HAPI: Hepatic artery pulsatility index; HVPG: Hepatic venous pressure gradient; LVI: Liver vascular index; NPV: Negative predictive value; PCl: Portal congestion index; PC/SD: Platelet count/spleen diameter ratio; PHI: Portal hypertensive index; PPV: Positive predictive value; PVD: Portal
}

vein diameter; PVFV: Portal vein flow velocity; SARI: Splenic artery resistance index; UGIE: Upper gastrointestinal endoscopy.

\section{Acknowledgements}

There is no acknowledgement.

\section{Authors' contributions}

$M N, M K, A A$ and ME contributed equally to study design, data collection, analysis, and interpretation of results. All authors read and approved the final manuscript.

\section{Funding}

There is no funding.

Availability for data and materials

Data will be available upon request via contacting the corresponding author.

\section{Declarations}

Ethics approval and consent to participate

All study procedures were conducted in accordance with Helsinki and were approved by the ethical committee of Menoufia Faculty of medicine council, reference number 10/2017-TROP-9. All patients and controls included in this research gave written informed consent to participate in this research.

\section{Consent for publication}

All patients included in this research gave written informed consent to publish the data contained within this study. If the patients were less than 16-yearold, deceased, or unconscious when consent for publication was requested, written informed consent for the publication of this data was given by their parents or legal guardians.

\section{Competing interests}

The authors declare that they have no competing interests.

\section{Author details}

${ }^{1}$ Department of Tropical Medicine, Menoufia University Faculty of Medicine, Shebeen El-Kom, Egypt. ${ }^{2}$ Department of Radiodiagnosis and Interventional Radiology, Menoufia University Faculty of Medicine, Shebeen El-Kom, Egypt.

Received: 24 June 2021 Accepted: 10 December 2021

Published online: 04 January 2022

\section{References}

1. De Franchis R (2005) Evolving consensus in portal hypertension report of the Baveno IV consensus workshop on methodology of diagnosis and therapy in portal hypertension. J Hepatol 43(1):167-176

2. Rani KV, Sudarsi B, Siddeswari R et al (2015) Correlation of portal vein size with esophageal varices severity in patients with cirrhosis of liver with portal hypertension. Int J Sci Res Publ 5(1)

3. Bhasin DK, Bhathal PS, Malhi NJS et al (2012) Variceal bleeding and portal hypertension: much to learn, much to explore. Endoscopy 34(02):119-128

4. American Association for the Study of Liver Diseases (2007) Guidelines for prevention and management of esophageal varices

5. Imperiale TF, Klein RW, Chalasani N (2007) Cost-effectiveness analysis of variceal ligation vs. beta-blockers for primary prevention of variceal bleeding. Hepatology 45(4):870-878

6. Franchis A, Cervantes-Guevara G, Chávez-Sánchez M et al (2015) Platelet count/spleen diameter ratio to predict esophageal varices in Mexican patients with hepatic cirrhosis. World J Gastroenterol 20(8):2079-2084

7. Sabba C, Merkel C, Zoli M et al (1995) Inter observer and intere quipment variability of echo-Doppler examination of the portal vein: effect of a cooperative training program. Hepatology 21:428-443

8. Moriyasu F, Nishida O, Ban N et al (2006) Measurement of portal vascular resistance in patients with portal hypertension. Gastroenterology 90:710-717 
9. Zhang L, Yin J, Duan Y et al (2011) Assessment of intrahepatic blood flow by Doppler ultrasonography: relationship between the hepatic vein, portal vein, hepatic artery and portal pressure measured intra operatively in patients with portal hypertension. BMC Gastroenterol 11(8):4-90

10. McNaughton DA, Abu-Yousef MM (2011) Doppler US of the liver made simple. Radio Graph 31(1):161-188

11. Sacerdoti D, Gaiani S, Buonamico P et al (2010) Inter observer and inter equipment variability of hepatic, splenic, and renal arterial Doppler resistance indices in normal subjects and patients with cirrhosis. J Hepatol 27:986-992

12. Shekar CG, Balaji B, Shekar CV et al (2016) Study of noninvasive predictors of oesophageal varices in chronic liver disease. Int J Res Pharmacol Pharmaco Ther 5(1):53-65

13. Paquet KJ (1982) Prophylactic endoscopic sclerosing treatment of the esophageal wall in varices, a prospective controlled randomized trial. Endoscopy 14:4-5

14. Madhotra R, Mulcahy HEl, Willner I et al (2002) Prediction of esophageal varices in patients with cirrhosis. J Clin Gastroenterol 34(1):81-85

15. Tharwa ES, Gamil K, Abdel-Samiee M et al (2017) A noninvasive panel for diagnosis of esophageal varices in patients with compensated cirrhosis. J Med Sci Clin Res 5(30):18747-18754

16. Hekmatnia A, Barikbin R, Farghadani M et al (2011) Prediction and screening of esophageal varices in cirrhotic patients using doppler US hemodynamic indices of portal system. Gastroenterol Insights 3(e4):11-14

17. Cherian JV, Deepak N, Ponnusamy RP et al (2011) Noninvasive predictors of esophageal varices. Saudi I Gastroenterol Off J Saudi Gastroenterol Assoc 17(1):64-68

18. Nashaat EH, Abd-Elaziz H, Sabry M et al (2010) Non endoscopic predictors of esophageal varices and portal hypertensive gastropathy. Nat Sci 8(6):43-50

19. Zaman A, Becker T, Lapidus J et al (2001) Risk factors for the presence of varices in cirrhotic patients without a history of variceal hemorrhage. Arch Intern Med 161(21):2564-2570

20. Faisal WI, Hasnain A, Saeed H et al (2008) Noninvasive predictors of large varices in patients hospitalized with gastroesophageal variceal hemorrhage. Hepatol Int 2(1):124-128

21. Khalil FA, Khalil KA, Khalil TH et al (2010) Evaluation of clinical, biochemical and ultrasound parameters in diagnosis of oesophageal varices. Med J Cairo Univ 78(2):105-109

22. Berzigotti A, Gilabert R, Abraldes JG et al (2008) Noninvasive prediction of clinically significant portal hypertension and esophageal varices in patients with compensated liver cirrhosis. Am J Gastroenterol 103:1159-1167

23. Anda AC, Bordei P, Dumitru E (2016) The role of Ultrasonography in the evaluation of portal hemodynamics in healthy adults and pathologic conditions. ARS Med Tomitana 2(22):128-134

24. Sarwar S, Khan AA, Alam A (2005) Non endoscopic prediction of presence of esophageal varices in cirrhosis. J Coll Phys Surg Park 15:528-531

25. Kayacetin E, Efe D, Doğan C (2004) Portal and splenic hemodynamics in cirrhotic patients: relationship between esophageal variceal bleeding and the severity of hepatic failure. J Gastroenterol 39(7):661-667

26. Jaheen A (2003) Prevalence of portal hypertensive gastropathy and its predictive factors. Gut Rev 3:24-33

27. Nouh AM, El-Hammoly SM, Mohamed AS et al (2019) The role of portal congestion index in prediction of esophageal varices in hepatitis $C$ virusinfected patients. Menoufia Med J 20:1-7

28. Agha A, Anwar E, Bashi K et al (2009) External validation of the platelet count/spleen diameter ratio for the diagnosis of esophageal varices in hepatitis C virus-related cirrhosis. Dig Dis Sci 54(3):654-660

29. Elhady AH, Hammam A, Elnimr A et al (2013) Evaluation of some noninvasive predictors for presence of esophageal varices in patients with compensated HCV positive cirrhosis. Int J Sci Res 5(1):461-468

30. Sheta EA, Yousef M, Abd-Elsalam S et al (2016) Non invasive diagnosis of esophageal varices: can it replace screening endoscopy. Int J Curr Microbiol Appl Sci 5(5):701-715

31. Mahmoud HS, Mostafa EF, Mohammed MA (2014) Role of portal haemodynamic parameters in prediction of oesophageal varices in cirrhotic patients. Arab J Gastroenterol 15(3-4):130-134

32. Liu C, Hsu S, Lang C et al (2008) Esophageal varices: noninvasive diagnosis with duplex Doppler US in patients with compensated cirrhosis. Radiology 248:132-139
33. Elbarbary AA, Elbedewy MM, Elbadry AM (2014) Hemodynamic analysis of portal hypertension in patients with liver cirrhosis. Tanta Med J 42(4):130-137

34. Schneider ARJ, Teuber G, Kriener $S$ et al (2005) Noninvasive assessment of liver steatosis, fibrosis and inflammation in chronic hepatitis $\mathrm{C}$ virus infection. Liver Int 25(6):1150-1155. https://doi.org/10.1111/J.1478-3231.2005. 01164.X

35. Piscaglia F, Marinelli S, Bota S et al (2014) The role of ultrasound elastographic techniques in chronic liver disease: current status and future perspectives. Eur J Radiol 83:450-455

36. Minal SS, Rushad P, Sarfaraz J (2014) Portal vein Doppler: a tool for noninvasive prediction of esophageal varices in cirrhosis. J Clin Diagn Res 8(7):MC12

37. Lee FH, Hao J, Xia JG et al (2016) Hemodynamic analysis of esophageal varices in patients with liver cirrhosis using color Doppler ultrasound. World J Gastroenterol 11:4560-4565

38. Park MY, Jung SE, Byun JY et al (2012) Effect of beam-flow angle on velocity measurements in modern doppler ultrasound systems. Am J Roentgenol Am Roentgen Ray Soc 198(5):1139-1143

39. Dewidar BI, Dessouky BAM, Mohamed Kl et al (2018) Evaluation of spleen stiffness compared to splenic artery resistive index as non invasive predictors for esophageal varices in patients with chronic liver disease. Gastroenterology 281(3):952-157

40. Nicolau C, Bianchi Land Vilana R (2002) Gray-scale ultrasound in hepatic cirrhosis and chronic hepatitis: diagnosis, screening, and intervention. Semin Ultrasound CT MR 23:3-18

41. Child CG, Turcotte JG (1964) Surgery and portal hypertension. In: Child CG (ed) The liver and portal hypertension. Saunders, Philadelphia, pp 50-64

42. Dib N, Konate A, Oberti F et al (2005) Noninvasive diagnosis of portal hypertension in cirrhosis. Gastroenterol Clin Biol 29:975-987

43. Haktanir A, Cihan BS, Çelenk Ç et al (2005) Value of Doppler sonography in assessing the progression of chronic viral hepatitis and in the diagnosis and grading of cirrhosis. J Ultrasound Med 24:311-321

44. Iwao T, Toyonaga A, Oho K et al (1997) Value of Doppler ultrasound parameters of portal vein and hepatic artery in the diagnosis of cirrhosis and portal hypertension. Am J Gastroenterol 34(6):343-347

45. Abu El Makarem MA, Shatat ME, Shaker Y et al (2011) Platelet count/bipolar spleen diameter ratio for the prediction of esophageal varices. The special Egyptian situation: noninvasive prediction of esophageal varices. Hepatitis Mon 11(4):278-284

46. Piscaglia F, Donati G, Serra C et al (2001) Value of splanchnic Doppler ultrasound in the diagnosis of portal hypertension. Ultrasound Med Biol 27(7):893-899

47. Jeon SW, Cho CM, Tak WY et al (2006) The value of Doppler-ultrasonography and laboratory tests as noninvasive predictors of the presence of esophageal varices in patients with chronic liver disease. Korean J Gastroenterol 48:180-187

\section{Publisher's Note}

Springer Nature remains neutral with regard to jurisdictional claims in published maps and institutional affiliations.

\section{Submit your manuscript to a SpringerOpen ${ }^{\circ}$ journal and benefit from:}

- Convenient online submission

- Rigorous peer review

- Open access: articles freely available online

- High visibility within the field

- Retaining the copyright to your article

Submit your next manuscript at springeropen.com 